\title{
CONTROLE DA MATURAÇÃO PRÉ-COLHEITA DE MAÇÃS 'ROYAL GALA' PELA INIBIÇÃO DA AÇÃO OU SÍNTESE DO ETILENO ${ }^{1}$
}

\author{
ANDREIA MARIA TOMAZINI SCOLARO², LUIZ CARLOS ARGENTA ${ }^{3}$, \\ CASSANDRO VIDAL TALAMINI DO AMARANTE ${ }^{4}$, JOSÉ LUIZ PETRI ${ }^{5}$, \\ FERNANDO JOSÉ HAWERROTH ${ }^{6}$
}

RESUMO - O objetivo deste trabalho foi avaliar os efeitos da inibição da ação (pela pulverização de 1-metilciclopropeno em meio aquoso; 1-MCP) e da síntese (pela pulverização de aminoetoxivinilglicina; AVG) do etileno, sobre a maturação pré-colheita de maçãs. Macieiras 'Royal Gala' foram pulverizadas com 1-MCP (50 ou $\left.100 \mathrm{mg} \mathrm{L}^{-1}\right)$ em meio aquoso ou com AVG (124 mg L-1), sete e 28 dias antes do ponto de colheita comercial dos frutos, respectivamente. Macieiras não tratadas com 1-MCP nem com AVG foram usadas como testemunha. As maçãs foram colhidas semanalmente, durante cinco semanas, a partir do sétimo dia após a aplicação do 1-MCP, e analisadas quanto à maturação e qualidade, um dia após a colheita. Índices de maturação e qualidade das maçãs, na data em que os frutos atingiram firmeza de 71,1 N, foram estimados por análise de regressão, para cada tratamento. Os tratamentos 1-MCP $\left(50\right.$ e $\left.100 \mathrm{mg} \mathrm{L}^{-1}\right)$ e AVG atrasaram a maturação das maçãs, diminuindo as taxas de produção de etileno, degradação do amido, perda de firmeza da polpa e da acidez, amarelecimento da epiderme, acúmulo de sólidos solúveis e desenvolvimento de cor vermelha. O tempo para os frutos atingirem firmeza de polpa de $71,1 \mathrm{~N}$ na planta foi retardado em 6 e 12 dias pelo 1-MCP $\left(100 \mathrm{mg} \mathrm{L}^{-1}\right)$ e AVG, respectivamente, em relação à testemunha. Maçãs tratadas com 1-MCP ou com AVG apresentaram índice de iodo-amido, produção de etileno e acidez semelhantes ou menores que maçãs testemunhas, nas datas em que os frutos de todos os tratamentos atingiram a mesma firmeza de 71,1 N. A magnitude do efeito do 1-MCP sobre a firmeza da polpa foi semelhante àquela sobre a produção de etileno e coloração da epiderme, mas sensivelmente menor que aquela sobre a degradação do amido. Os efeitos do AVG sobre a produção de etileno, coloração da epiderme e acidez foram maiores que aqueles sobre a redução da firmeza da polpa. Os resultados mostram que a pulverização de macieiras com 1-MCP em meio aquoso representa um método adicional de manejo da maturação para escalonamento da colheita de maçãs 'Royal Gala'.

Termos para indexação: Malus domestica Borkh, etileno, 1-metilciclopropeno, aminoetoxivinilglicina, colheita.

\section{PREHARVEST CONTROL OF 'ROYAL GALA' APPLE FRUIT MATURATION BY THE INHIBITION OF ETHYLENE ACTION OR SYNTHESIS}

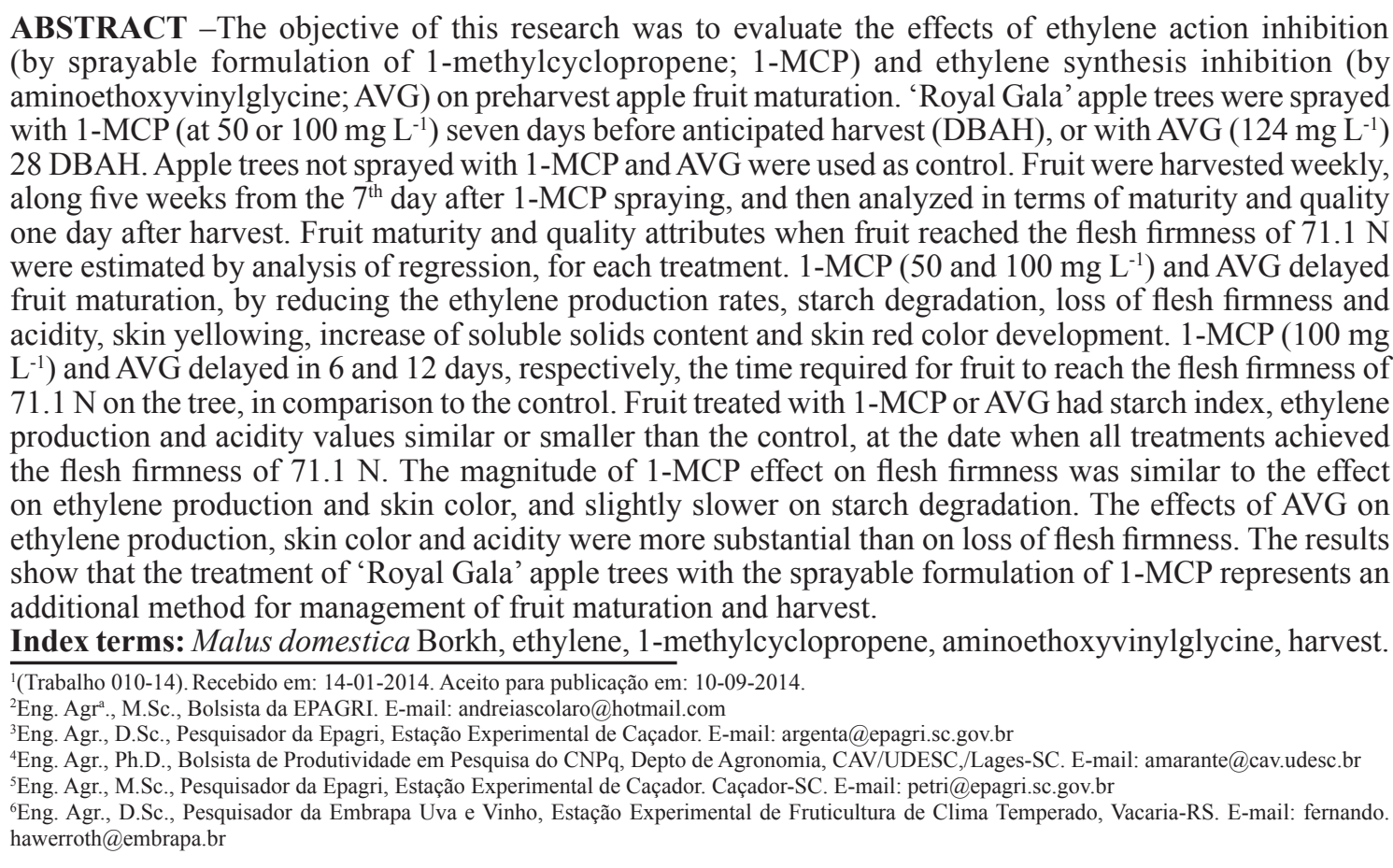

Rev. Bras. Frutic., Jaboticabal - SP, v. 37, n. 1, p. 038-047, Março 2015 


\section{INTRODUÇÃO}

A cultivar 'Gala' e seus clones representam aproximadamente $65 \%$ da produção brasileira de maçãs, estimada em 1,34 milhão de toneladas em 2011 (FAOSTAT, 2013). Em razão da grande área de exploração e produtividade de maçãs 'Gala', e da rápida maturação na planta, parte da produção dos frutos é, inevitavelmente, colhida após o período de maturação ideal para armazenamento em longo prazo, o que resulta em menor vida pós-colheita dos frutos e alto índice de perda da produção por deterioração (ARGENTA; MONDARDO, 1994). Além disso, a abscisão pré-colheita dos frutos, antes de atingirem cor vermelha e tamanho exigidos pelo mercado, resulta em perdas significativas da produção (PETRI et al., 2007). Por isso, o escalonamento da colheita, pelo manejo da maturação de maçãs 'Gala' na planta, permite reduzir as perdas da produção antes da colheita e durante a armazenagem, visando ao aumento da rentabilidade econômica.

A colheita comercial dos frutos é determinada principalmente por atributos de qualidade (como coloração vermelha e tamanho dos frutos) e de maturação (como firmeza de polpa, índice de iodoamido e cor de fundo da epiderme). Segundo Argenta e Mondardo (1994), no ponto ideal de colheita de maçãs 'Gala' destinadas a longos períodos de armazenagem, o índice de iodo-amido (escala 1-9) deve estar entre 3,5 e 5,5, enquanto a firmeza da polpa deve estar entre 84,4 e 75,6 N (19 e 17 lb). No entanto, segundo estes autores, para médios períodos de armazenagem, o período ideal de colheita de maçãs 'Gala' termina quando os frutos atingem firmeza de polpa de 71,1 N (16 lb).

O composto aminoetoxivinilglicina (AVG), um inibidor da biossíntese do etileno, tem sido aplicado comercialmente em pomares de macieiras, como tecnologia para escalonamento da maturação e colheita dos frutos (LURIE, 2005). A pulverização de macieiras com AVG retarda a degradação do amido, a perda de firmeza da polpa, o amarelecimento e o desenvolvimento de coloração avermelhada da epiderme, além de retardar a abscisão dos frutos (SCHUPP; GREENE, 2004; BYERS et al., 2005; GREENE, 2005; YUAN; CARBAUGH, 2007; AMARANTE et al., 2010). O 1-metilciclopropeno (1-MCP) é inibidor da ação do etileno e tem sido aplicado comercialmente, em câmaras herméticas, para retardar o amadurecimento e a senescência póscolheita de frutos de várias espécies, incluindo maçã (LURIE, 2005; HUBER, 2008). O 1-MCP aumenta a conservação da firmeza da polpa e da acidez titulável (AT), e previne o desenvolvimento de alguns distúrbios fisiológicos, tais como a escaldadura superficial e o escurescimento senescente da polpa de maçãs (WATKINS, 2008).

Pesquisas recentes indicam que 1-MCP em meio aquoso, pulverizado às macieiras, pode ter pequeno ou nenhum efeito sobre a maturação e a abscisão dos frutos na planta, dependendo da cultivar, região produtora e época de colheita, embora possa aumentar a conservação das maçãs durante a armazenagem (BYERS et al., 2005; ELFVING et al., 2007; McARTNEY et al., 2009; DeELL; EHSANIMOGHADDAM, 2010). Entretanto, outros estudos mostram que a aplicação pré-colheita de 1-MCP pode retardar significativamente a maturação de maçãs 'Law Rome', 'Bisbee Delicious'e 'Golden Delicious' na planta, bem como a abscisão dos frutos (YUAN; CARBAUGH, 2007; YUAN; LI, 2008; McARTNEY et al., 2008; VARANASI et al., 2013).

O presente estudo foi desenvolvido para avaliar os efeitos da pulverização pré-colheita de macieiras 'Royal Gala' com inibidor da ação (1-MCP em meio aquoso) ou síntese (AVG) do etileno, sobre a maturação dos frutos.

\section{MATERIAL E MÉTODOS}

O estudo foi conduzido em um pomar comercial de macieira, localizado no município de Fraiburgo-SC $\left(27^{\circ} 01^{\prime} 34^{\prime \prime} \mathrm{S}, 50^{\circ} 55^{\prime} 17^{\prime}\right.$ ' W - altitude de $1.048 \mathrm{~m}$ ), no ano de 2006. Foi utilizado um pomar com macieiras 'Royal Gala', sobre porta-enxerto M-26, implantado em 1996, com densidade de 3.300 plantas $\mathrm{ha}^{-1}$. As plantas foram manejadas de acordo com a recomendações do sistema de produção integrada da macieira.

Macieiras foram pulverizadas com 1-MCP em meio aquoso (1-metilciclopropeno-ciclodextrina, AgroFresh Inc.), nas doses de 50 ou 100 mg (i.a.) $\mathrm{L}^{-1}$, ou com AVG (aminoetoxivinilglicina, Valent BioSciences Inc.), na dose de $124 \mathrm{mg}$ (i.a.) $\mathrm{L}^{-1}$. Frutos de macieiras não pulverizadas foram usados como testemunha.

A aplicação do AVG (com a adição de espalhante adesivo Silwet ${ }^{\circledR}, 0,05 \%$; v/v) foi realizada com pulverizador costal motorizado, equipado com bico Leque DS, aplicando-se volume de calda de $1.000 \mathrm{~L} \mathrm{ha}^{-1}$, a 0,68 MPa, 28 dias antes da data prevista para a colheita comercial dos frutos não tratados. A previsão da data de colheita comercial foi realizada com base na data da plena floração e considerando que o ponto de colheita comercial de maçãs 'Gala' normalmente ocorre 117 dias após a plena floração (ARGENTA; MONDARDO, 1994).

O 1-MCP em meio aquoso (com a adição 
de óleo mineral Assist ${ }^{\circledR}, 1 \%$; v/v) foi aplicado com pulverizador costal pressurizado com $\mathrm{CO}_{2}$, equipado com bico Leque OC-12. Pulverizaram-se aproximadamente $1.200 \mathrm{~L} \mathrm{ha}^{-1}$, a $0,42 \mathrm{MPa}$, sete dias antes da data prevista para a colheita comercial dos frutos não tratados.

Os frutos foram colhidos semanalmente, durante quatro semanas, sendo que a primeira colheita ocorreu sete dias após a aplicação do 1-MCP (DAAM). Frutos de apenas uma planta por bloco foram amostrados em cada data de colheita, sendo a colheita dos frutos realizada uma única vez em cada planta. Em cada data de colheita, foram amostrados 50 frutos por planta, para análise da maturação e da qualidade, 24 horas após a colheita.

As maçãs foram analisadas quanto a: taxa respiratória (evolução de $\mathrm{CO}_{2}$ ) e de produção de etileno; firmeza de polpa; índice de iodo-amido; acidez titulável (AT); sólidos solúveis (SS); intensidade de cor vermelha; e coloração de fundo da epiderme.

Para a determinação da taxa respiratória e de produção de etileno, amostras de aproximadamente $1 \mathrm{~kg}$ de frutos foram colocadas em jarras de $4 \mathrm{~L}$, supridas com ar comprimido, livre de etileno, a 100

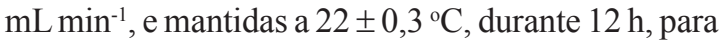
a estabilização da temperatura. As concentrações de $\mathrm{CO}_{2}$ e etileno no ar efluente foram coletadas usandose seringas e determinadas com um cromatógrafo a gás, equipado com metanador, dois detectores de ionização de chama, uma coluna de aço para o $\mathrm{CO}_{2}$ (com comprimento de $1,0 \mathrm{~m}$ e diâmetro interno de $2,0 \mathrm{~mm}$ ) e uma coluna de vidro para etileno (com comprimento de $0,6 \mathrm{~m}$ e diâmetro interno de 3,2 $\mathrm{mm}$ ), ambas as colunas empacotadas com Poropak Q 80-100 mesh. As temperaturas do forno, detectores, metanador e injetor foram de $45 ; 120 ; 300$ e $110^{\circ} \mathrm{C}$, respectivamente.

A firmeza da polpa (N) foi medida em dois lados opostos da superfície de cada fruto, na região equatorial, após a remoção da casca, pela utilização de um penetrômetro com ponteira de 11 mm (Güss, África do Sul). O índice de iodo-amido foi avaliado numa escala de 1 (secção transversal da polpa corada com iodo, indicando alto teor de amido e fruto imaturo) a 9 (secção transversal da polpa não corada com iodo, indicando baixo teor de amido e fruto maduro). Os valores de AT e SS foram determinados através de suco preparado com espremedor tipo Champion (Plastaket Mgf, CA). A AT (\% de ácido málico) foi determinada utilizando-se de $5 \mathrm{~mL}$ do suco do fruto, diluído em $20 \mathrm{~mL}$ de água destilada, sendo esta solução titulada com $\mathrm{NaOH}$ $0,1 \mathrm{~N}$ até $\mathrm{pH} 8,1$, usando um titulador automático
(Radiometer, Copenhagen, Dinamarca). O teor de SS (\%) foi medido usando-se refratômetro digital, com compensação automática de temperatura (Atago, Japão). A intensidade de cor vermelha (\% de área avermelhada relativa à superfície total do fruto) e a coloração de fundo [escala de 1 (verde) a 5 (amarelolaranja), na região não avermelhada da superfície do fruto] da epiderme foram avaliadas subjetivamente, através de análise visual.

No momento da aplicação do AVG, as maçãs apresentavam firmeza da polpa de 100,4 $\pm 3,2 \mathrm{~N}$ e índice de iodo-amido de 1,2 $\pm 0,3$, sendo que, na aplicação do 1-MCP, as maçãs apresentavam firmeza da polpa de $84,3 \pm 4,9 \mathrm{~N}$ e índice de iodo-amido de $2,9 \pm 0,5$.

O delineamento experimental utilizado foi em blocos casualizados, com quatro repetições, cada repetição composta de uma planta, seguindo esquema fatorial (4 x 5), obtido da combinação de quatro tratamentos (testemunha, 1-MCP $50 \mathrm{mg} \mathrm{L}^{-1}$, 1-MCP $100 \mathrm{mg} \mathrm{L}^{-1}$ e AVG $124 \mathrm{mg} \mathrm{L}^{-1}$ ) e cinco datas ( $7 ; 14 ; 21 ; 28$ e 35 DAAM) de colheita dos frutos.

Os dados foram submetidos à análise de variância, usando o programa SAS (SAS Institute, Inc.). Médias de tratamentos foram comparadas pelo teste de Tukey $(\mathrm{p}<0,05)$, e os efeitos datas de avaliação (DAAM) foram analisados através de análise de regressão polinomial $(\mathrm{p}<0,05)$. O número de DAAM em que os frutos atingiram firmeza da polpa de $71,1 \mathrm{~N}$, considerado valor mínimo de colheita de maçãs 'Gala' para armazenamento refrigerado de média duração (ARGENTA; MONDARDO, 1994), foi estimado usando-se equações de regressão, ajustadas para cada tratamento. O número de DAAM, quando os índices de maturação e qualidade dos frutos corresponderam à firmeza de polpa de 71,1 $\mathrm{N}$ na planta, foi estimado por análise de regressão, para cada tratamento.

\section{RESULTADOS E DISCUSSÃO}

Houve atraso na maturação dos frutos, nas plantas tratadas com 1-MCP (em ambas as doses) e $\mathrm{AVG}$, conforme evidenciado pelo retardo no aumento das taxas respiratórias e de produção de etileno, na degradação do amido, no amarelecimento da área não avermelhada da superfície e na perda da firmeza de polpa, em relação à testemunha (Figuras 1 e 2). $\mathrm{O}$ uso do 1-MCP, independentemente da dose, retardou o desenvolvimento de cor vermelha na superfície dos frutos, embora esse efeito tenha sido mais pronunciado quando aplicado o AVG (Figura 2B). Tanto o 1-MCP (nas duas doses) quanto o AVG não alteraram substancialmente a velocidade de redução 
da AT (Figura 2C) e de aumento do teor de SS (Figura 2D), com o atraso na colheita.

Os efeitos dos tratamentos com 1-MCP (nas duas doses) e AVG na redução da produção de etileno (Figura 1A) e na preservação da firmeza da polpa (Figura 2A), em comparação à testemunha, foram mais evidentes nos frutos colhidos tardiamente, ao passo que, para o retardo na degradação do amido (menor aumento no índice de iodo-amido) (Figura 1B), os efeitos foram maiores nos frutos colhidos precocemente.

O AVG inibe a produção de etileno e retarda a maturação de maçãs na planta (GREENE, 2005; YILDIZ et al., 2012), embora esse efeito não ocorra para algumas cultivares tardias, como 'Fuji', que apresentam baixa taxa de produção de etileno (LURIE, 2005; AMARANTE et al., 2010).

A capacidade do 1-MCP em retardar a maturação de maçãs em plantas tratadas também tem sido demonstrada recentemente. A pulverização pré-colheita de 1-MCP em macieiras, sete a 14 dias antes da colheita comercial, em doses de 45 a 396 $\mathrm{mg} \mathrm{L}^{-1}$, promove redução na produção de etileno e retardo na degradação do amido (ELFVING et al., 2007; YUAN; CARBAUGH, 2007; YUAN; LI, 2008), bem como redução na taxa de perda de firmeza da polpa dos frutos (YUAN; CARBAUGH, 2007; McARTNEY et al., 2008). No entanto, o 1-MCP aplicado em pré-colheita também pode diminuir ou não afetar a perda de firmeza da polpa em maçãs, dependendo da dose e do ano (YUAN; LI, 2008), da região de produção (McARTNEY et al., 2008; 2009) e da cultivar (ELFVING et al., 2007; DeELL; EHSANI-MOGHADDAM, 2010).

Assim como observado no presente estudo, em maçãs 'Royal Gala' (Figuras 1D e 2C), 1-MCP retardou o amarelecimento da epiderme em 'Golden Delicious' (YUAN; CARBAUGH, 2007, McARTNEY et al., 2008), mas não afetou a AT em maçãs 'Delicious' e 'Cameo' (ELFVING et al., 2007). Em maçãs 'Honeycrisp', a AT não foi afetada ou foi bastante reduzida pelo 1-MCP, dependendo do ano, da época de aplicação do produto e da data de colheita dos frutos (DeELL; EHSANI-MOGHADDAM, 2010). A intensidade de coloração avermelhada foi diminuída pela aplicação pré-colheita de 1-MCP em maçãs 'Royal Gala' (Figura 2B), o mesmo tendo sido reportado em maçãs 'Scarlerspur Delicious' (ELFVING et al., 2007), mas não em maçãs 'Delicious' (YUAN; LI, 2008) e 'Arlet' (BYERS et al., 2005).

Frutos das plantas tratadas com 1-MCP mantiveram, em relação à testemunha, maior firmeza de polpa (até 28 DAAM) e cor de fundo mais verde (até 35 DAAM), e menores valores de índice de iodo-amido (aos 7; 14 e 28 DAAM) e de taxa de produção de etileno (aos 21; 28 e 35 DAAM), independentemente da dose (Figuras 1 e 2).

Frutos de plantas tratadas com $100 \mathrm{mg} \mathrm{L}^{-1} \mathrm{de}$ 1-MCP apresentaram menor índice de iodo-amido, aos 14 e 21 DAAM, e maior firmeza de polpa, aos 14 e 35 DAAM, que frutos de plantas tratadas com $50 \mathrm{mg} \mathrm{L}^{-1}$ de 1-MCP (Figuras 1B e 2A). Nos demais DAAM, esses índices de maturação não foram alterados pelo aumento da dose de 1-MCP. Por outro lado, não houve efeito significativo de dose de 1-MCP sobre o amarelecimento da epiderme e o teor de SS, independentemente de DAAM, exceção para 21 DAAM, quando frutos de plantas tratadas com $50 \mathrm{mg} \mathrm{L}^{-1}$ apresentaram coloração mais esverdeada que frutos de plantas tratadas com $100 \mathrm{mg} \mathrm{L}^{-1}$ (Figuras 1D e 2D). Esses resultados indicam que a dose de $100 \mathrm{mg} \mathrm{L}^{-1}$ de 1 -MCP pode ser sensivelmente mais efetiva que a dose de 50 $\mathrm{mg} \mathrm{L}^{-1}$, para o retardamento de alguns processos relacionados à maturação de maçãs 'Royal Gala', dependendo da data de colheita. $\mathrm{O}$ aumento da dose de 1 -MCP de 50 para $100 \mathrm{mg} \mathrm{L}^{-1}$ não afetou de forma significativa e consistente o desenvolvimento da cor vermelha (Figura 2B).

As variações da firmeza da polpa em função do número de DAAM ajustaram-se a modelos lineares de regressões $(p<0,01)$, para os quatro tratamentos testados (Tabela 1). Esses modelos lineares de regressões permitiram estimar o número de DAAM em que os frutos atingiram firmeza da polpa de $71,1 \mathrm{~N}$.

Por meio das regressões lineares (Tabela 1), estimou-se que frutos de macieiras 'Royal Gala' não tratadas (testemunha) e tratadas com 1-MCP na dose de $100 \mathrm{mg} \mathrm{L}^{-1}$ ou AVG atingiriam firmeza da polpa de 71,1 $\mathrm{N}$ aos 13; 19 e 25 DAAM, respectivamente (Figura 2A). Dessa forma, evidenciou-se que os tratamentos com 1-MCP na dose de $100 \mathrm{mg}$ $\mathrm{L}^{-1}$ e $\mathrm{AVG}$ podem retardar a colheita de maçãs 'Royal Gala' por 6 e 12 dias, respectivamente, se considerarmos firmeza de polpa de 71,1 N. Portanto, o 1-MCP possibilita o escalonamento da colheita de maçãs, assim como já demonstrado por pulverização com AVG (GREENE, 2005; AMARANTE et al., 2010; YILDIZ et al., 2012). Em macieiras 'Gala', existem relatos de que o AVG retarda o início da colheita dos frutos, baseando-se na análise da firmeza de polpa, em 5 a 14 dias (PHAN-THIEN et al., 2004; AMARANTE et al., 2010), dependendo do ano.

$\mathrm{O}$ escalonamento da colheita pelo controle da maturação com reguladores de crescimento 
é uma maneira de prevenir a colheita de maçãs sobremaduras, especialmente quando não há escalonamento por diversificação de cultivares, como é o caso do Brasil, e quando condições climáticas desfavoráveis e/ou insuficiência de mão de obra impedem a colheita no período ideal (PETRI et al., 2007). A colheita de frutos sobremaduros implica redução do potencial (tempo) de armazenagem e/ou aumento dos riscos de perda da produção durante a armazenagem, por deterioração dos frutos. Adicionalmente, o escalonamento da colheita permite redução de custos de colheita e recepção dos frutos nos parques de armazenagem, classificação e empacotamento.

Assim como observado para firmeza da polpa, a variação dos demais indicadores da maturação e da qualidade das maçãs, em função do número de DAAM, ajustaram-se a modelos lineares de regressões $(p<0,01)$ (Tabela 1$)$, à exceção das taxas respiratórias (Figura 1C). Os modelos lineares de regressões foram usados para estimar os índices de maturação e qualidade dos frutos, de cada tratamento, nos DAAM em que eles atingiram firmeza da polpa de $71,1 \mathrm{~N}$.

Através dos modelos ajustados, observase que frutos de macieiras tratadas com 1-MCP na dose de $100 \mathrm{mg} \mathrm{L}^{-1}$ ou AVG podem apresentar índice de iodo-amido ligeiramente inferior àquele de frutos em macieiras não tratadas (testemunha), quando os frutos dos três tratamentos são colhidos com firmeza de polpa de 71,1 N (Figura 1B). Adicionalmente, maçãs de plantas tratadas com AVG podem apresentar menores valores de produção de etileno, AT e intensidade de cor vermelha, e cor de fundo menos amarelecida que maçãs de plantas não tratadas, quando os frutos de ambos os tratamentos são colhidos com firmeza de polpa de $71,1 \mathrm{~N}$ (Figuras 1 e 2). Todavia, para estes atributos, não há diferença entre a testemunha e o tratamento com 1-MCP na dose de $100 \mathrm{mg} \mathrm{L}^{-1}$, quando os frutos dos dois tratamentos são colhidos com firmeza de polpa de 71,1 N (Figuras 1 e 2). Esses resultados mostram que alguns indicadores da maturação podem não ser igualmente afetados pelos tratamentos com 1-MCP e AVG.

Tem sido observado que a efetividade da aplicação pré-colheita de AVG em retardar o aumento da produção de etileno e a degradação do amido são maiores que para retardar a perda de firmeza da polpa em maçãs (PHAN-THIEN et al., 2004). Maçãs de plantas tratadas com AVG apresentam menor acúmulo de antocianinas e de degradação da clorofila na epiderme (GREENE, 2005; LURIE, 2005; AMARANTE et al., 2010). A inibição na síntese do etileno pelo AVG pode atrasar ou inibir a expressão de genes da biossíntese de antocianinas, resultando em forte atraso e diminuição da coloração avermelhada da epiderme de maçãs (AMARANTE et al., 2010).

Os resultados do presente estudo demonstram que 1-MCP em meio aquoso, pulverizado em macieiras 'Royal Gala', retarda a maturação dos frutos, podendo ser uma ferramenta adicional ao AVG, atualmente usado comercialmente. Ressalta-se que a duração dos efeitos do 1-MCP pode ser menor do que aquela observada com o uso do AVG, e que as alterações físico-químicas associadas ao fenômeno da maturação, tais como a perda de firmeza de polpa e a degradação do amido, podem ser levemente dessincronizadas. 
$\begin{array}{lll}\text { - Testemunha } & \square & 1-\mathrm{MCP}, 100 \mathrm{mg} \cdot \mathrm{L}^{-1} \\ \text { - } 1-\mathrm{MCP}, 50 \mathrm{mg} \cdot \mathrm{L}^{-1} & \wedge & \mathrm{AVG}\end{array}$

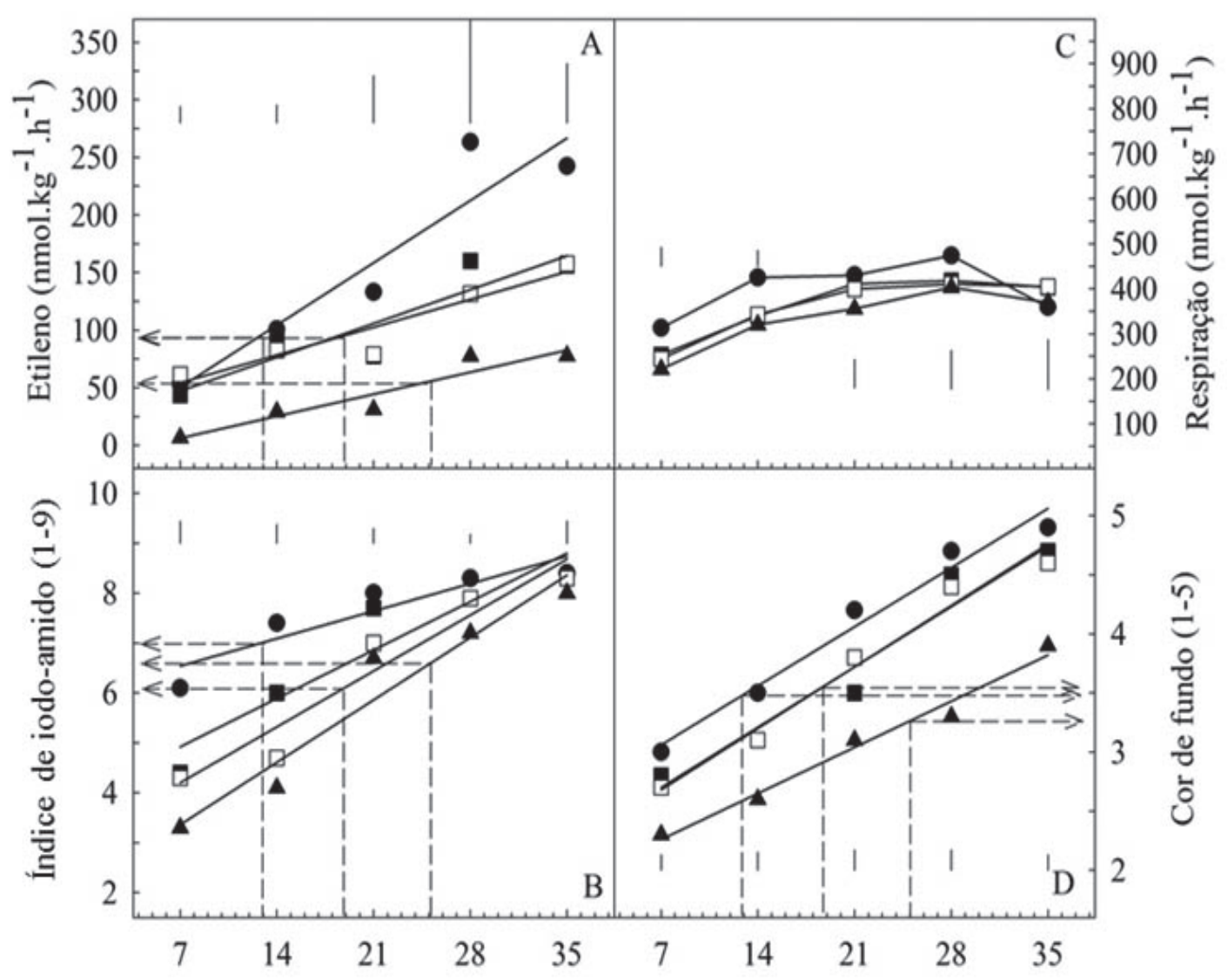

Dias após a aplicação do 1-MCP

FIGURA 1 - Taxa de produção etileno (A), índice de iodo-amido (escala de 1 a 9) (B), taxa de respiração (C), e índice de cor de fundo [escala de 1 (verde) a 5 (amarelo-laranja)] (D), em função da data de colheita dos frutos (dias após a aplicação de 1-metilciclopropeno; 1-MCP), em macieiras 'Royal Gala' não tratadas (Testemunha) e tratadas com 1-MCP (50 ou $100 \mathrm{mg}$ $\mathrm{L}^{-1}$ ) e aminoetoxivinilglicina (AVG; $124 \mathrm{mg} \mathrm{L}^{-1}$ ). As barras verticais internas representam a diferença mínima significativa entre tratamentos, determinadas pelo teste de Tukey $(\mathrm{p}<0,05)$. Setas indicam as taxas de produção de etileno e os índices de iodo-amido e de cor de fundo na data em que as maçãs apresentavam firmeza da polpa de $71,1 \mathrm{~N}$, estimados pela análise de regressão (Tabela1). 


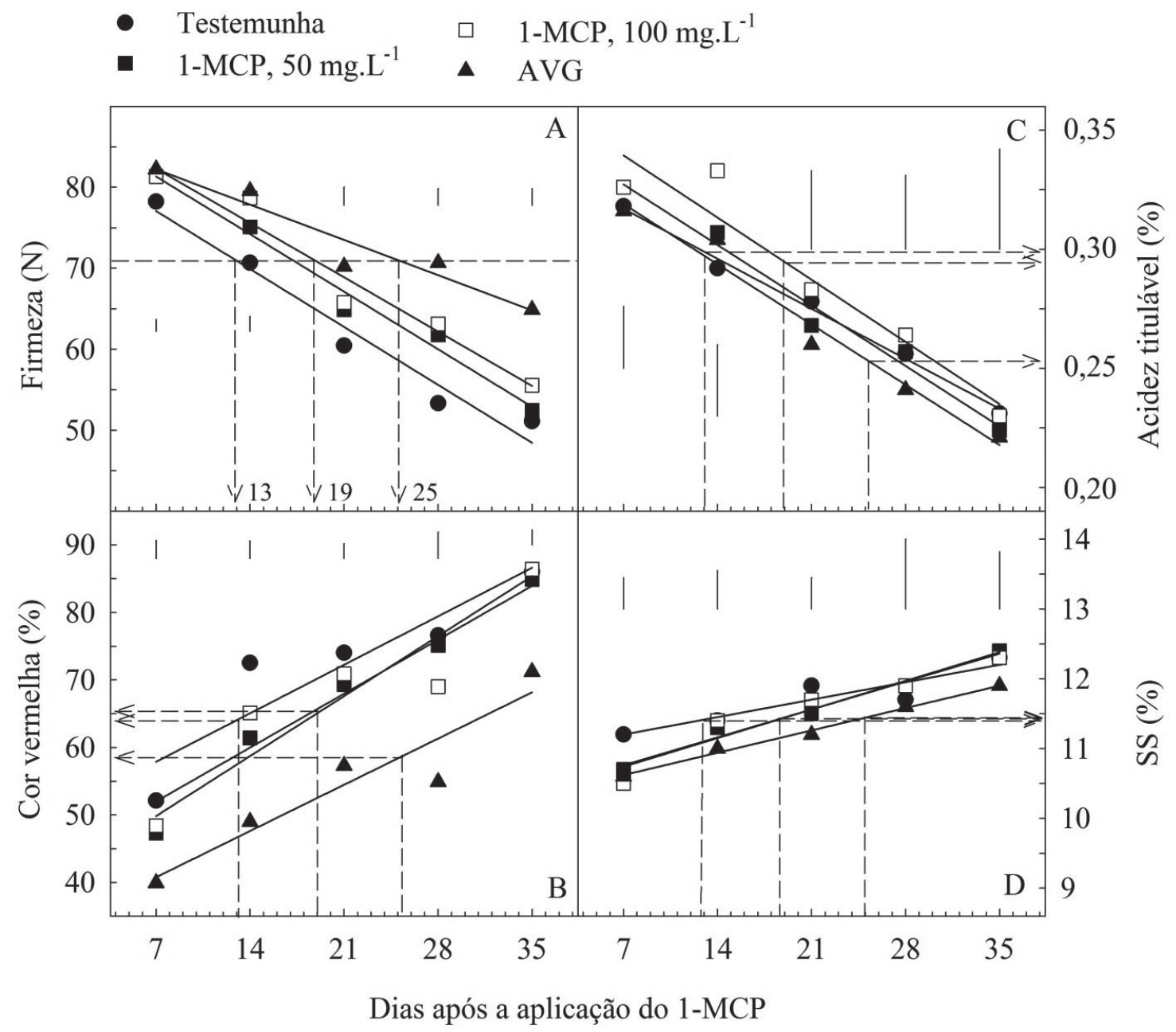

FIGURA 2 - Firmeza da polpa (A), porcentagem de cor vermelha (B), acidez titulável (C) e teor de sólidos solúveis (SS) (D), em função da data de colheita dos frutos (dias após a aplicação de 1-metilciclopropeno; 1-MCP), em macieiras 'Royal Gala' não tratadas (Testemunha) e tratadas com 1-MCP ( 50 ou $100 \mathrm{mg} \mathrm{L}^{-1}$ ) e aminoetoxivinilglicina (AVG; $124 \mathrm{mg} \mathrm{L}^{-1}$ ). As barras verticais internas representam a diferença mínima significativa entre tratamentos, determinadas pelo teste de Tukey $(\mathrm{p}<0,05)$. Setas verticais no interior do gráfico de firmeza de polpa indicam a data em que as maçãs de cada tratamento atingiram $71,1 \mathrm{~N}$. As setas horizontais nos demais gráficos indicam a porcentagem de cor vermelha e os valores de acidez titulável e SS, na data em que as maçãs apresentavam firmeza da polpa de $71,1 \mathrm{~N}$, estimados pela análise de regressão (Tabela 1). 
TABELA 1 - Modelos lineares para variações nos atributos da maturação e qualidade de maçãs 'Royal Gala', em função das datas de colheita (dias após a aplicação do 1-MCP aquoso), para cada tratamento.

\begin{tabular}{|c|c|c|c|c|}
\hline \multirow{2}{*}{ Atributo } & \multirow{2}{*}{ Tratamento } & \multicolumn{3}{|c|}{ Modelos Lineares } \\
\hline & & Significância & $a$ & $b$ \\
\hline \multirow{4}{*}{ Firmeza $(\mathrm{N})$} & Testemunha & $* *$ & 84,22 & 1,022 \\
\hline & 1-MCP, $50 \mathrm{mg} \mathrm{L}^{-1}$ & $* *$ & 88,44 & $-1,016$ \\
\hline & 1-MCP, $100 \mathrm{mg} \mathrm{L}^{-1}$ & $* *$ & 89,02 & $-0,959$ \\
\hline & AVG, $124 \mathrm{mg} \mathrm{L}^{-1}$ & $* *$ & 86,59 & $-0,622$ \\
\hline \multirow{4}{*}{ Índice de iodo-amido (1-9) } & Testemunha & $* *$ & 5,99 & 0,079 \\
\hline & 1-MCP, $50 \mathrm{mg} \mathrm{L}^{-1}$ & $* *$ & 3,95 & 0,139 \\
\hline & 1-MCP, $100 \mathrm{mg} \mathrm{L}^{-1}$ & $* *$ & 3,08 & 0,160 \\
\hline & AVG, $124 \mathrm{mg} \mathrm{L}^{-1}$ & $* *$ & 2,11 & 0,179 \\
\hline \multirow{4}{*}{ Acidez Titulável (\%) } & Testemunha & $* *$ & 0,338 & $-0,0030$ \\
\hline & 1-MCP, $50 \mathrm{mg} \mathrm{L}^{-1}$ & $* *$ & 0,353 & $-0,0036$ \\
\hline & 1-MCP, $100 \mathrm{mg} \mathrm{L}^{-1}$ & $* *$ & 0,366 & $-0,0037$ \\
\hline & $\mathrm{AVG}, 124 \mathrm{mg} \mathrm{L}^{-1}$ & $* *$ & 0,344 & $-0,0036$ \\
\hline \multirow{4}{*}{ Sólidos Solúveis (\%) } & Testemunha & $* *$ & 11,0 & 0,036 \\
\hline & 1-MCP, $50 \mathrm{mg} \mathrm{L}^{-1}$ & $* *$ & 10,4 & 0,057 \\
\hline & 1-MCP, $100 \mathrm{mg} \mathrm{L}^{-1}$ & $* *$ & 10,3 & 0,059 \\
\hline & $\mathrm{AVG}, 124 \mathrm{mg} \mathrm{L}^{-1}$ & $* *$ & 10,3 & 0,046 \\
\hline \multirow{4}{*}{ Cor de fundo (1-5) } & Testemunha & $* *$ & 2,56 & 0,0714 \\
\hline & 1-MCP, $50 \mathrm{mg} \mathrm{L}^{-1}$ & $* *$ & 2,16 & 0,0743 \\
\hline & 1-MCP, $100 \mathrm{mg} \mathrm{L}^{-1}$ & $* *$ & 2,19 & 0,0729 \\
\hline & $\mathrm{AVG}, 124 \mathrm{mg} \mathrm{L}^{-1}$ & $* *$ & 1,87 & 0,0557 \\
\hline \multirow{4}{*}{ Cor vermelha (\%) } & Testemunha & $* *$ & 50,67 & 1,027 \\
\hline & 1-MCP, $50 \mathrm{mg} \mathrm{L}^{-1}$ & $* *$ & 40,93 & 1,270 \\
\hline & 1-MCP, $100 \mathrm{mg} \mathrm{L}^{-1}$ & $* *$ & 43,99 & 1,140 \\
\hline & AVG, $124 \mathrm{mg} \mathrm{L}^{-1}$ & $* *$ & 33,91 & 0,979 \\
\hline \multirow{4}{*}{ Etileno $\left(\eta \mathrm{Mol} \mathrm{kg}{ }^{-1} \mathrm{~h}^{-1}\right)$} & Testemunha & $* *$ & $-3,77$ & 7,727 \\
\hline & 1-MCP, $50 \mathrm{mg} \mathrm{L}^{-1}$ & $* *$ & 17,68 & 4,194 \\
\hline & 1-MCP, $100 \mathrm{mg} \mathrm{L}^{-1}$ & $* *$ & 30,13 & 3,447 \\
\hline & AVG, $124 \mathrm{mg} \mathrm{L}^{-1}$ & $* *$ & $-12,90$ & 2,729 \\
\hline
\end{tabular}

**: modelo linear significativo a $1 \%$ de probabilidade.

$a$ e $b$ : coeficientes do modelo linear $(\mathrm{y}=a+b \mathrm{x})$.

\section{CONCLUSÕES}

Tratamentos pré-colheita com 1-MCPaquoso (sete dias antes da colheita) e AVG (28 dias antes da colheita) atrasam a maturação de maçãs, diminuindo a produção de etileno e retadando a degradação do amido, a perda de firmeza da polpa, o amarelecimento da superfície dos frutos e o aumento da coloração avermelhada.

A duração do atraso da maturação pelo 1-MCP é menor que a do AVG, considerando o tempo (dias) para que maçãs de plantas não tratadas e tratadas com 1-MCP ou AVG atinjam o mesmo valor de firmeza de polpa $(71,1 \mathrm{~N})$.
Efeito do 1-MCP sobre a degradação do amido é ligeiramente maior que aquele sobre a perda de firmeza da polpa.

Efeitos do AVG sobre a produção de etileno, cor vermelha e acidez titulável são maiores que aqueles sobre a perda de firmeza da polpa.

\section{AGRADECIMENTOS}

À Associação Brasileira de Produtores de Maçã (ABPM) e à AgroFresh Inc., Dow AgroSciences, pelo suporte técnico e financeiro a esse estudo. 


\section{REFERÊNCIAS}

AMARANTE, C.V.T.; STEFFENS, C.A.; BLUM, L.E.B. Coloração do fruto, distúrbios fisiológicos e doenças em maçãs 'Gala' e 'Fuji' pulverizadas com aminoetoxivinilglicina. Revista Brasileira de Fruticultura, Jaboticabal, v.32, n.1, p.9-18, 2010.

ARGENTA, L.C.; MONDARDO, M. Maturação na colheita e qualidade de maçãs 'Gala' após a armazenagem. Revista Brasileira de Fisiologia Vegetal, São Carlos, v.6, n.2, p.135-140, 1994.

BYERS, R.E.; CARBAUGH, D.H.; COMBS, L.D. Ethylene inhibitors delay fruit drop, maturity, and increase fruit size of 'Arlet' apples. HortScience, Alexandria, v.40, n.7, p.2061-2065, 2005.

DeELL, J.R.; EHSANI-MOGHADDAM, B. Preharvest 1-methylcyclopropene treatment reduces soft scald in 'Honeycrisp' apples during storage. HortScience, Alexandria, v.45, n.3, p.414-417, 2010.

ELFVING, D.C.; DRAKE, A.N.; REED, A.N.; VISSER, D.B. Preharvest applications of sprayable 1-methylcyclopropene in the orchard for management of apple harvest and postharvest condition. HortScience, Alexandria, v.42, n.5, p.1192-1999, 2007.

FAOSTAT. Statistical databases. Disponível em: $\leq$ http://faostat.fao.org/site/567/ DesktopDefault. aspx?PageID=567\#ancor $>$. Acesso em: 11 set. 2013.

GREENE, D.W. Time of aminoethoxyvinylglycine application influences preharvest drop and fruit quality of 'McIntosh' apples. HortScience, Alexandria, v.40, n.7, p.2056-2060, 2005.

HUBER, D.J. Suppression of ethylene responses through application of 1-methylcyclopropene: A powerful tool for elucidating ripening and senescence mechanisms in climacteric and nonclimacteric fruits and vegetables. HortScience, Alexandria, v.43, n.1, p.106-111, 2008.

LURIE, S. Regulation of ethylene biosynthesis in fruits by aminoethoxyvinylglycine and 1 -methylcyclopropene. Stewart Postharvest Review, Quebec, v.1, n.3, p.1-8, 2005.
McARTNEY, S.J.; OBERMILLER, J.D.; HOYT, T.; PARKER, M.L. 'Law Rome' and 'Golden Delicious' apples differ in their response to preharvest and postharvest 1-methylcyclopropene treatment combinations. HortScience, Alexandria, v.44, n.6, p.1632-1636, 2009.

McARTNEY, S.J.; SCHUPP, J.; PARKER, M.; OBERMILLER, J.D.; EDGINGTON, T. Preharvest 1 -methylcyclopropene delays fruit maturity and reduces softening and superficial scald of apples during long-term storage. HortScience, Alexandria, v.43, n.2, p.366-371, 2008.

PETRI, J.L.; LEITE, G.B.; ARGENTA, L.C. Eficácia do tratamento de AVG no controle da queda e maturação dos frutos de maçã, cultivar Imperial Gala. Revista Brasileira de Fruticultura, Jaboticabal, v.29, n.2, p.239-244, 2007.

PHAN-THIEN, K.Y.; WARGO, J.M.; MITCHELL, L.W.; COLLETT, M.G.; RATH, A.C. Delay in ripening of 'Gala' and 'Pink Lady' apples in commercial orchards following pre-harvest applications of aminoethoxyvinylglycine. Australian Journal of Experimental Agriculture, Victoria, v.44, n.8, p.807-812, 2004.

SCHUPP, J.R.; GREENE, D.W. Effect of aminoetoxyniniylglycine (AVG) on preharvest drop, fruit quality and maturation of 'McIntosh' apples. I. Concentration and timing of dilute applications of AVG. HortScience, Alexandria, v.39, n.5, p.10301035, 2004.

VARANASI, V.; SHIN, S.; JOHNSON, F.; MATTHEIS, J.P.; ZHU, Y. Differential suppression of ethylene biosynthesis and receptor genes in 'Golden Delicious' apple by preharvest and postharvest 1-MCP treatments. Journal of Plant Growth Regulation, New York, v.32, n.3 , p.585595, 2013.

WATKINS, C.B. Overview of 1-methylcyclopropene trials and uses for edible horticultural crops. HortScience, Alexandria, v.43, n.1, p.86-94, 2008.

YILDIZ, K.; OZTURK, B.; OZKAN, Y. Effects of aminoethoxyvinilglycine (AVG) on preharvest fruit drop, fruit maturity, and quality of 'Red Chief' apple. Scientia Horticulturae, Amsterdam, v.144, n.1, p.121-124, 2012. 
YUAN, R.; CARBAUGH, D.H. Effects of NAA, YUAN, R.; LI, J. Effect of sprayable 1-MCP, AVG AVG, and 1-MCP on ethylene biosynthesis, and NAA on ethylene biosynthesis, preharvest fruit preharvest fruit drop, fruit maturity, and quality of drop, fruit maturity and quality of 'Delicious' apples. 'Golden Supreme’ and 'Golden Delicious' apples. HortScience, Alexandria, v.43, n.5, p.1454-1460, HortScience, Alexandria, v.42, n.1, p.101-105, 2007. 2008. 